\title{
Perception, knowledge and attitudes of Brazilian orthodontists on the treatment of Class II malocclusions
}

\section{ARMANDO K. KAIEDA ${ }^{1}$, IGOR F.P. LIMA ${ }^{2}$, MARCO ANTÔNIO SCANAVINI ${ }^{3}$, RAILDO S. COQUEIRO ${ }^{4}$, MATHEUS M. PITHON ${ }^{4}$, SIGMAR M. RODE $^{5}$ and LUIZ RENATO PARANHOS ${ }^{2}$}

\author{
${ }^{1}$ Departamento de Odontologia Social, Faculdade de Odontologia de Piracicaba, Universidade Federal \\ de Campinas/UNICAMP, Avenida Limeira, 901, 13414-018 Piracicaba, SP, Brazil \\ ${ }^{2}$ Departamento de Odontologia, Universidade Federal de Sergipe, Avenida Governador \\ Marcelo Déda Chagas, 13, 49400-000 Lagarto, SE, Brazil \\ ${ }^{3}$ Programa de Pós-Graduação em Odontologia, Universidade Metodista, Rua Alfeu \\ Tavares, 149, 09641-000 São Bernardo do Campo, SP, Brazil \\ ${ }^{4}$ Departamento de Saúde, Universidade Estadual do Sudoeste da Bahia, Avenida \\ José Moreira Sobrinho, 638, 45205-490 Jequié, BA, Brazil \\ ${ }^{5}$ Instituto de Ciência e Tecnologia, Departamento de Materiais Dentários e Prótese, Universidade Estadual Paulista Júlio \\ de Mesquita Filho, Avenida Engenheiro Francisco José Longo, 777, 12201-970 São José dos Campos, SP, Brazil
}

Manuscript received on July 22, 2017; accepted for publication on August 9, 2017

\begin{abstract}
The present study aimed to assess the perception and knowledge of Brazilian orthodontists on the ideal moment to treat Class II malocclusions. Questionnaires with open, semi-open and close questions were sent by e-mail to 1653 Brazilian orthodontists. These orthodontists were registered in the Brazilian Association of Orthodontics and Dentofacial Orthopedics (ABOR). One-hundred and three (9.86\%) Orthodontists replied to the questionnaires. Most of them were males (60.5\%) with specialization as the highest level of professional qualification (59.9\%). Most of the orthodontists (51\%) reported preference for treating Class II malocclusions in late mixed dentition, followed by the early mixed dentition (29\%). The age range between 10 and 12 years old figured as the most prevalent in patients searching for treatment $(42.7 \%)$. Most of the patients searching for treatment were females (69.7\%). Preferences for functional orthopedic appliances were reported by $35 \%$ of the orthodontists. Brazilian orthodontists revealed a trend for treating patients with Class II malocclusions in the late mixed dentition. Female patients aged from 10 to 12 years old represented the majority of patients that search for orthodontic treatment. Functional orthopedic appliances were preferred by Brazilian orthodontists for treating Class II malocclusions.
\end{abstract}

Key words: orthodontic appliances, attitudes, diagnosis, Class II malocclusion.

Correspondence to: Luiz Renato Paranhos

E-mail: paranhos.lrp@gmail.com 


\section{INTRODUCTION}

Class II malocclusions are represented by the distal occlusal position of the lower molars in relation to their antagonist. This malocclusion may be classified within divisions 1 and 2, which are based on the inclination of the upper central incisors (Angle 1899). Class II malocclusion is not the most prevalent malocclusion in Brazilian patients (Brasil 2012). However, it figures as one of the most common reasons behind the search for orthodontic treatment (Quaglio et al. 2009). Epidemiological studies (Quaglio et al. 2009, Bittencourt and Machado 2010, Brasil 2012) point towards Class I malocclusion as the most prevalent, while Class II is often associated with important aesthetic (Cançado et al. 2009, Bittencourt and Machado 2010), functional, psychological and social consequences (Bittencourt and Machado 2010).

Uncertainty lies on the ideal time to treat Class II malocclusions (Cançado et al. 2009). Two main protocols have been applied for this purpose the early intervention within two phases, and the late intervention within a single phase. The first consists in an initial treatment stage with functional orthopedic appliances during the mixed dentition and a second stage with fixed appliances in the permanent dentition (Silva-Filho et al. 2005). Ideally, patients treated with this protocol should be aged before adolescence. In this age period optimal outcomes may achieved treating the overjet, overbite and the alignment of incisors (first phase). Next, in the adolescence additional corrections may be performed in the remaining discrepancies (second phase) (King et al. 1990). The literature defends this protocol justifying that it assures major stability and corrects the malocclusion through the control of dental and skeletal growth (Dugoni and Lee 1995, White 1998).

On the other hand, the late intervention is founded on the correction of the malocclusion in the permanent dentition in a single phase (without orthopedic therapeutics) (Cançado et al. 2009). In this protocol, skeletal and dental corrections are performed simultaneously (Calheiros et al. 2008). This protocol emerged as an alternative to the lack of patient cooperation in early interventions, as well the high cost of these interventions (dental movement is less evident before the pubertal growth spurt, which makes the treatment last longer) (Calheiros et al. 2008). Additionally, adepts of this protocol suggest that the orthodontic control over skeletal and dental growth is merely hypothetical (Franchi et al. 1999, Bendeus et al. 2002). Thus, establishing the ideal therapeutic protocol depends on the psychological and financial capacities of the patient, the duration and stability of the treatment (Proffit and Tulloch 2002, Popowich et al. 2005) and the individual characteristics of each case based on clinical and cephalometric evidences (Gimenez et al. 2007).

In face of the high demand for orthodontic treatment of Class II malocclusions, the two therapeutic protocols - double and single phases - were questioned on their clinical effectiveness (Bremen and Pancherz 2002). The present study was justified considering I) the uncertainty in the scientific literature on the treatment of patients with Class II malocclusion; II) the lack of information on the ideal moment for treating these patients in Brazil; and III) the lack of information on the systems/appliances used by Brazilian orthodontists in the treatment of Cass II malocclusions.

\section{MATERIALS AND METHODS}

\section{ETHICAL CRITERIA}

The present study was conducted after the approval of the local Committee of Ethics in Research (protocol number: CEP - 3415570-09; CAAE 0117.0.214.000.09). 


\section{STUDY DESIGN}

A prospective transversal study was designed. A questionnaire with open, semi-open, and close questions was developed. The inherent responses to these questions could be subjective, semi-subjective and objective. The questionnaires were sent via e-mail to 1653 Brazilian orthodontists registered in the Brazilian Association of Orthodontics and Facial Orthopedics (ABOR). Sample size calculation was not performed in the present study because the authors expected to reach initially all the orthodontists registered in ABOR. Information such as age, sex, level of Professional qualification, the time experience with Orthodontics, the place of graduation and the time since graduation were retrieved from the professionals.

A second part of the questionnaire was designed to investigate objectively the ideal moment in which the orthodontists prefer to treat patients with Class II malocclusion. The questions in this part concerned not only the ideal moment to treat these patients, but also if the dentists observe benefits in the early intervention, especially if it reduces the need for extractions in the second phase; if the early intervention reduces treatment duration in the second phase; if the intervention increases stability and alignment of the lower incisors; if the orthodontists considered the patients age below 10 years old more cooperative than adolescents; and if the orthodontists believe that the first phase influences in the second phase.

Open (subjective) questions investigated the most prevalent sex and age group searching for treatment of Class II malocclusions; the prevalence of cases treated in the first phase; and the most used systems and appliances.

Semi-open (semi-subjective) questions were designed to investigate conditions in which the early intervention could be hampered, such as the lack of patient cooperation, poor oral hygiene, and the lack of financial conditions. An open field was added to these questions in which the orthodontists could include other limiting conditions.

\section{INSTRUMENT AND DATA EXTRACTION}

A pilot test was designed to validate an instrument for data collection and to estimate the mean time taken for the application of this instrument. In this research part, the instrument was sent to fifteen orthodontists in the State of São Paulo. These professionals were not included in the main sample.

After 7 days, the instrument was sent a second time to the same orthodontists. The agreement between the two applications of the instrument was assessed and correlated with Spearman's Correlation Coefficient. Eleven (73.33\%) orthodontists out of the 15 responded identically to the questionnaires in both moments. Good correlation was observed in this test (ranging from 0.07 to 1 ) and suggested a satisfactory reproducibility.

METHODOLOGY

After the pilot study, the questionnaire was sent via e-mail to the orthodontists sampled from ABOR. The questionnaires were sent together with the research informed consent and the researcher responsibility file.

In total, 1653 e-mails were sent. Responses to these e-mails were expected within the following 30 days. After this period, identical e-mails were sent to the orthodontists that did not reply to the first contact. Responses to the second e-mail were expected within 15 days. After 45 days (between first and second e-mails) 163 orthodontists replied $(9.86 \%)$.

\section{DATA ANALYSIS}

The data obtained was expressed with absolute (n) and relative (\%) frequencies. Spearman's Correlation Coefficient was applied to assess the reproducibility in the pilot study. 
Chi-square test was performed to associate each answer in the questionnaires with the level of professional qualification and experience of the orthodontists. Fisher exact test was used to investigate the answers in which the frequency expected was below $5(n<5)$. Statistic tests were performed with a significance level of $5 \%(\alpha=0.05)$ using SPSS 21.0 (IBM Corp., Armonk, NY, USA) software package.

\section{RESULTS}

Out of the 1653 e-mails sent to the Brazilian Orthodontists registered in $\mathrm{ABOR}$, one hundred and three $(9.86 \%)$ were replied. Table I shows that the sample addressed in the present study consisted of Orthodontists aged between 23 and 82 years old (mean age: 39.9 years \pm 10.3 ) years (23 to 82 years). Their time of experience in Orthodontics ranged from 1 to 54 years (mean time of experience: 13.0 years \pm 9.0) (Table I).

Table II brings information on the orthodontic management of Class II malocclusions. Most of the orthodontists prefer the late intervention - within mixed dentitions. A lower prevalent rate was observed regarding orthodontic treatment in the permanent dentition. Most of the patients searching for orthodontic treatment of Class II malocclusions were females aged between 10 and 12 years old. Children age between 4 and 6 years old were less prevalent. According to most of the orthodontists, the early intervention reduces the need for premolar extractions and potentially reduces the treatment time in the second phase. Orthodontists' opinions on the influence of early intervention in the stability and alignment of lower incisors were similarly divided. The outcomes also indicate that orthodontists consider the children aged below 10 years old more cooperative than adolescents. The orthodontic appliance most reported to treat Class II malocclusions was the functional orthopedic; followed by the combination of extraoral and
TABLE I

Characteristics of the orthodontists investigated in the present study.

\begin{tabular}{cccc}
\hline Characteristics & Response rate (\%) & n & \% \\
\hline Sex & 99.4 & & \\
Male & & 98 & 60.5 \\
Female & & 64 & 39.5 \\
Level of professional & & & \\
qualification & 99.4 & & \\
Specialization & & 97 & 59.9 \\
Master degree & & 38 & 23.5 \\
Doctoral degree & & 27 & 16.7 \\
Time of professional & 95.7 & & \\
experience* & & & \\
<9 years & & 56 & 35.9 \\
10-16 years & & 53 & 34.0 \\
$>16$ years & 47 & 30.1 \\
\hline
\end{tabular}

n: absolute outcomes; \%: outcomes; *: classification founded on terciles.

functional orthopedic; distalizers (exclusively); the combination of extraoral and distalizers; and the combination of functional orthopedic and distalizers. According to the orthodontists, the main condition limiting the treatment of Class II malocclusions is the lack of patient cooperation.

The stage of dental development preferred for treating Class II malocclusions was associated with the level of professional qualification and the time of professional experience in Orthodontics (Table III). Preference for treating in the early mixed dentition was more prevalent among professionals with a Master degree, followed by specialists. Professionals with $\mathrm{PhD}$ degree preferred the treatment in the late mixed dentition, followed by specialists. The treatment of patients with deciduous dentition was more prevalent within professionals with more than 16 years of experience in Orthodontists. Professionals with time of experience between 10 and 16 years and less than 9 years preferred patients in the permanent dentitions.

All the other responses provided by the orthodontists were not statistically significant 
TABLE II

Outcomes of the questions concerning the treatment of Class II malocclusions.

\begin{tabular}{|c|c|c|c|}
\hline Items questioned & Response rate $(\%)$ & $\mathbf{n}$ & $\%$ \\
\hline Ideal moment to treat CIIM & 95.1 & & \\
\hline Deciduous dentition & & 8 & 5.2 \\
\hline Early mixed dentition & & 45 & 29.0 \\
\hline Late mixed dentition & & 79 & 51.0 \\
\hline Permanent dentition & & 21 & 13.5 \\
\hline Adult phase & & 1 & 0.6 \\
\hline All the moments described above & & 1 & 0.6 \\
\hline Most prevalent age range of the patients searching for the treatment of CIIM & 71.8 & & \\
\hline 4-6 years old & & 4 & 3.4 \\
\hline $7-8$ years old & & 29 & 24.8 \\
\hline 10-12 years old & & 50 & 42.7 \\
\hline 13-16 years old & & 19 & 16.2 \\
\hline$>16$ years old & & 15 & 12.8 \\
\hline Most prevalent sex of the patients searching for the treatment of CIIM & 93.3 & & \\
\hline Male & & 20 & 13.2 \\
\hline Female & & 106 & 69.7 \\
\hline Male and Female & & 26 & 17.1 \\
\hline Impact of the early intervention on reducing the need for premolar extraction & 99.4 & & \\
\hline Yes (reduction in the need for extractions) & & 140 & 86.4 \\
\hline No (no reduction in the need for extractions) & & 22 & 13.6 \\
\hline The early intervention reduces the treatment duration in the second phase & 96.9 & & \\
\hline Yes & & 138 & 87.3 \\
\hline No & & 20 & 12.7 \\
\hline The early intervention increases stability and improves dental alignment & 94.5 & & \\
\hline Yes & & 89 & 57.8 \\
\hline No & & 65 & 42.2 \\
\hline Patients aged $<10$ years old are more cooperative than adolescents & 95.7 & & \\
\hline Yes & & 108 & 69.2 \\
\hline No & & 48 & 30.8 \\
\hline The first phase of the treatment influences on the second & 98.2 & & \\
\hline Yes & & 148 & 92.5 \\
\hline No & & 12 & 7.5 \\
\hline Prevalence of cases treated in the first phase & 82.2 & & \\
\hline$<30 \%$ & & 52 & 38.5 \\
\hline $30-60 \%$ & & 65 & 48.1 \\
\hline$>60 \%$ & & 18 & 13.3 \\
\hline Types of systems/appliances used more frequently & 93.9 & & \\
\hline
\end{tabular}


TABLE II (continuation)

\begin{tabular}{|c|c|c|c|}
\hline Items questioned & Response rate $(\%)$ & $\mathbf{n}$ & $\%$ \\
\hline Extraoral & & 17 & 11.1 \\
\hline Functional & & 54 & 35.3 \\
\hline Extraoral + functional & & 47 & 30.7 \\
\hline Distalizalizers & & 3 & 2.0 \\
\hline Extraoral + Distalizalizers & & 6 & 3.9 \\
\hline Extraoral + functional + Distalizalizers & & 18 & 11.8 \\
\hline Functional + Distalizalizers & & 8 & 5.2 \\
\hline Limiting conditions for the early intervention & 98.8 & & \\
\hline Patient's cooperation & & 76 & 47.2 \\
\hline Oral hygiene & & 2 & 1.2 \\
\hline Financial conditions & & 7 & 4.3 \\
\hline Patient's cooperation + oral hygiene & & 15 & 9.3 \\
\hline Patient's cooperation + financial conditions & & 17 & 10.6 \\
\hline Oral Hygiene + financial conditions & & 0 & 0.0 \\
\hline Other & & 44 & 27.3 \\
\hline
\end{tabular}

CIIM: Class II malocclusion; n: absolute outcomes; \%: outcomes.

TABLE III

Association of the ideal moment to treat Class II malocclusions with the level of professional qualification and with the time of professional experience.

\begin{tabular}{|c|c|c|c|c|c|c|c|}
\hline \multirow{2}{*}{ Variable } & \multicolumn{6}{|c|}{ Ideal moment to treat } & \multirow{2}{*}{$* p$} \\
\hline & DD & EMD & LMD & PD & $\mathbf{A P}$ & All & \\
\hline \multicolumn{8}{|l|}{ Level of qualification } \\
\hline Specialization & $\begin{array}{c}5 \\
(5.4 \%)\end{array}$ & $24(26.1 \%)$ & $46(50.0 \%)$ & $16(17.4 \%)$ & $0(0.0 \%)$ & $1(1.1 \%)$ & \\
\hline Master degree & $\begin{array}{c}3 \\
(8.1 \%)\end{array}$ & $17(45.9 \%)$ & $13(35.1 \%)$ & $\begin{array}{c}3 \\
(8.1 \%)\end{array}$ & $1(2.7 \%)$ & $0(0.0 \%)$ & 0.034 \\
\hline Doctoral degree & $\begin{array}{c}0 \\
(0.0 \%)\end{array}$ & $\begin{array}{c}4 \\
(16.0 \%)\end{array}$ & $19(76.0 \%)$ & $\begin{array}{c}2 \\
(8.0 \%)\end{array}$ & $0(0.0 \%)$ & $0(0.0 \%)$ & \\
\hline \multicolumn{8}{|l|}{ Time of experience } \\
\hline$\leq 9$ years & $\begin{array}{c}3 \\
(5.5 \%)\end{array}$ & $14(25.5 \%)$ & $26(47.3 \%)$ & $11(20.0 \%)$ & $1(1.8 \%)$ & $0(0.0 \%)$ & \\
\hline $10-16$ years & $\begin{array}{c}0 \\
(0.0 \%)\end{array}$ & $14(28.6 \%)$ & $28(57.1 \%)$ & $\begin{array}{c}7 \\
(14.3 \%)\end{array}$ & $0(0.0 \%)$ & $0(0.0 \%)$ & 0.006 \\
\hline$>16$ Years & $5(10.9 \%)$ & $15(32.6 \%)$ & $25(54.3 \%)$ & $\begin{array}{c}0 \\
(0.0 \%)\end{array}$ & $0(0.0 \%)$ & $1(2.2 \%)$ & \\
\hline
\end{tabular}

DD: deciduous dentition; EMD: early mixed dentition; LMD: late mixed dentition; PD: permanent dentition; AP: adult phase; *p-value for Fisher's exact test with a significance level of $5 \%$. 
for the association $(\mathrm{p} \geq 0.05)$ with the level of professional qualification and the time of professional experience.

The sample Power reported in Table III reached 0.98. It indicates that type II error (in both associations observed in this study) was well controlled and the probability of statistical differences being found by chance was remote. Based on that, the associations performed in the present study had statistical power enough to support the conclusions.

\section{DISCUSSION}

Several protocols are reported in the scientific literature for the treatment of Class II malocclusions. Consequently, divergence in therapeutic opinions exists. Knowing the treatment protocols available is important to promote optimal clinical outcomes. The present study is justified to assess the knowledge and perception of orthodontists on the ideal moment to treat patients with Class II malocclusion and to screen the inherent systems and appliances. The present study highlighted a trend in Brazil for the orthodontic treatment of Class II malocclusions in the late mixed dentition. It reflects on the therapeutic concern with the pubertal growth spurt and the conservative treatment with functional orthopedic appliances.

According to SB Brasil (Brasil 2012), the prevalence of Class I malocclusions in deciduous dentition reaches $77.1 \%$ of the population, followed by Class II (16.6\%) and Class III 6.4\% malocclusions. Similarly, an epidemiological survey (Bittencourt and Machado 2010) with 4.776 Brazilian children age from 6 to 10 years old showed a prevalence rate of $18.4 \%$ of Class II malocclusions. Despite not the most prevalent, Class II malocclusion is one of the most common reasons behind the search for orthodontic treatment (Quaglio et al. 2009).
Since 1980 the population of dentists in Brazil is predominantly female (56.3\%) (Mott et al. 2008). However, in specific specialties, such as Orthodontics, men are the most prevalent (Paranhos et al. 2009). The present study corroborates the literature expressing a prevalence rate of $60.5 \%$ for men. On the other hand, the literature indicates a possible change of the scenario in Orthodontics (Nunes et al. 2010), in which women reveal major interest in the search for training. Confirming the literature (Paranhos et al. 2011), specialization was the most prevalent level of professional qualification among orthodontists in the present study (59.9\%). This finding is justified on the increasing number of specialization courses in Brazil (Paranhos et al. 2008).

The ideal moment to start the orthodontic treatment in patients with Class II malocclusion lacks consensus in the scientific literature (Cançado et al. 2009). Depending on the treatment choice, the pubertal growth spurt may be conserving an important landmark for triggering treatments (Ruf and Pancherz 2003). In the present study most of the Brazilian orthodontists preferred the treatment in the (early or late) mixed dentition, confirming the importance of the pubertal growth spurt (Kopecky and Fishman 1993, Ruf and Pancherz 2003). These outcomes also reflect in the age of major prevalence (from 10 to 12 ) reported by the orthodontists in relation to the patients in treatment for Class II malocclusions. Also in accordance with the literature (Kopecky and Fishman 1993, Caprioglio et al. 2017, Pontes et al. 2017), 69.7\% of the orthodontists indicated that most of the patients in the search for treatment were females. Probably, the high prevalence rate of females is explained on the fact that women concern more about health (Spalj et al. 2017). The search for the treatment of Class II malocclusions currently remains mostly on aesthetic concerns. It also justify the search for treatment among females aged between 10 and 12 
years old - period of mixed dentition (Costa-Júnior and Maia 2009, Pietila and Pietila 1994).

The diversity of protocols for the treatment of Class II malocclusions culminates with the uncertainty of orthodontists in the therapeutic appliances available and their effects in the dentition (Cançado et al. 2009). Thus, the orthodontic treatment will depend on the etiology of the malocclusion, the age of the patients and their clinical and facial characteristics. Choosing the adequate treatment protocol plays an essential part in the final occlusal relation and facial harmony (Sharma 2009). Orthognatic surgery (Gimenez et al. 2007), dental extractions, fixed orthodontics appliances (Faber and Salles 2006) and functional orthopedic appliances in a single or double phases (Siara-Olds et al. 2010) figure as the most common treatment options available (Al-Jewair et al. 2012).

The treatment protocol in a single phase is founded on the use of fixed orthodontic appliances in patients with permanent teeth fully erupted (Cançado et al. 2009). Some professionals state that the protocol in two phases relies on hypothetical developmental control - justifying the use of a single phase approach (Basciftci et al. 2003, Ciger et al. 2005, Marques et al. 2005). Additionally, they state that long-term treatments compromise patient cooperation and hamper the second phase of the treatment (Wieslander 1993, Livieratos and Johnston 1995). The literature is also uncertain whether or not the protocol with two phases leads to more post-treatment stability (Barrer 1971). In specific, the protocol with two phases usually starts in the mixed or deciduous dentition with functional orthopedic appliances and progress to the second phase with fixed appliances installed in permanent teeth (Cançado et al. 2009). This protocol is justified in the literature on the potential orthodontic control over bone development (Dugoni and Lee 1995, White 1998). The literature shows no evident difference between the two treatments. In the present study, a large part of the orthodontists reported preference for the treatment in two phases (Dolce et al. 2005, Pavlow et al. 2008). When questioned on the influence of the first phase in the second, most of orthodontists $(92.5 \%)$ responded positively. Their opinion corroborates the literature (Silva-Filho et al. 2005, Dolce et al. 2005).

On the other hand, it is important to highlight that growth is conducted genetically. The protocols founded on controlling growth work opposite to the pre-established genetic expression (da SilvaFilho et al. 2009). Reflecting on the limitations of this protocol is important due to the difficulties for modifying skeletal and facial morphology. The orthodontist must know the role of genetics in the treatment chosen for each patient (Singer 1980).

The association between the opinion on the ideal moment for treatment and the level of professional qualification (Table III), a trend for treating late mixed dentitions was observed among orthodontists with higher degree of qualification. However, this finding was not statistically significant. Considering the time of professional experience, the three age ranges considered $(\leq$ $9,10-16$ and $>16$ years old) revealed preference for treating Class II malocclusions during the late mixed dentition. It is justified on the concern with the pubertal growth spurt, the severity of the malocclusion (Dugoni 1998, Pavlow et al. 2008) and its psychological impact in young patients (Livieratos and Johnston 1995).

Among the several systems and appliances available for treating Class II malocclusions, the functional orthopedic appliances are the most used, especially because mandibular deficiency figures as the most prevalent etiology in these patients (Ngan et al. 1997). With a functional and orthopedic biomechanics, these appliances are effective for patients in development (Gimenez et al. 2007). The present study indicated a highly prevalent use of orthopedic appliances (Table II), even in association with extraoral systems. It suggests that Brazilian orthodontists are concerned on benefit optimally 
from the pubertal growth spurt for treating Class II malocclusions. Differently, distalizers were less prevalent even with a conservative approach (Higa and Henriques 2015). The low prevalence rate of distalizers is justified possibly in the need for patient cooperation. The same is observed with extraoral and removable appliances. This aspect is confirmed when the orthodontists are questioned on the potential conditions that could hamper early interventions. In this context, $47.2 \%$ orthodontists reported the lack of patient cooperation (Table II).

Orthodontic treatment may be a stressful situation, in which the patient is exposed to new experiences that may cause physical or psychological discomfort (Possobon et al. 2004). Consequently, they may not cooperate as expected. In the present study, $69.2 \%$ of the orthodontists believe that patients aged below 10 years old are more cooperative than adolescents. These outcomes confirm the literature (Weiss and Eiser 1977, Bowman 1998). Adolescents often express high anxiety rates in face of their vulnerability to eventual biological and social experiences (da Silva-Filho and da Silva 2013). Yet anxiety may justify the outcomes of the present study.

A limitation that could affect the present study relies on the interpretation of Class II malocclusion. Despite explained clearly in the questionnaire, Class II malocclusion could be interpreted on skeletal relations instead dental (occlusal) relation. Further studies could be performed to confirm the present findings and extrapolate the investigation of the knowledge, perception and attitudes of orthodontists in face of other malocclusions and even skeletal discrepancies.

The present study expressed limitations not inherent to the etiology of Class II or type of facial pattern. The different interpretation of dental or skeletal problems was a confounding bias that could influence while answering to the questionnaire. Further studies should be performed to confirm the present findings and to support the diagnosis and therapeutic protocols for Class II malocclusion in Orthodontics. The present study shows that Brazilian Orthodontists prefer to treat Class II malocclusions in the late mixed dentition. It highlights a concern with the ideal moment for intervention considering patient's growth. These outcomes were also confirmed by their preference for functional orthopedic appliances.

\section{CONCLUSIONS}

Brazilian orthodontists revealed preference for treating patients with Class II malocclusion in the stage of late mixed dentition.

Females aged between 10 and 12 years old represent most of the patients searching for orthodontic treatment of Class II malocclusion.

Functional orthopedic appliances are the most used for the treatment of Class II malocclusions.

\section{REFERENCES}

AL-JEWAIR TS, PRESTON CB, MOLL EM AND DISCHINGER T. 2012. A comparison of the MARA and the AdvanSync functional appliances in the treatment of Class II malocclusion. Angle Orthod 82: 907-914.

ANGLE EH. 1899. Classification of malocclusion. Dent Cosmos 41: 248-264.

BARRER HG. 1971. Treatment timing--onset or onslaught? J Clin Orthod 5: 191-199.

BASCIFTCI FA, UYSAL T, BÜYÜKERKMEN A AND SARI Z. 2003. The effects of activator treatment on the craniofacial structures of Class II division 1 patients. Eur J Orthod 25: 87-93.

BENDEUS M, HAGG U AND RABIE B. 2002. Growth and treatment changes in patients treated with a headgearactivator appliance. Am J Orthod Dentofacial Orthop 121: 376-384.

BITTENCOURT MAV AND MACHADO AW. 2010. Prevalência de má oclusão em crianças entre 6 e 10 anos - um panorama brasileiro. Dental Press J Orthod 15: 113122.

BOWMAN SJ. 1998. One-stage versus two-stage treatment: are two really necessary? Am J Orthod Dentofacial Orthop 113: 111-116.

BRASIL. 2012. Ministério da Saúde. SB Brasil 2010: Pesquisa Nacional de Saúde Bucal: resultados principais. Brasília, Ministério da Saúde. 
BREMEN JV AND PANCHERZ H. 2002. Efficiency of early and late Class II Division 1 treatment. Am J Orthod Dentofacial Orthop 121: 31-37.

CALHEIROS AA, MIGUEL JAM, MOURA PM AND ALMEIDA MAO. 2008. Tratamento da má oclusão de Classe II de Angle em duas fases: avaliação da efetividade e eficácia por meio do índice par. R Dental Press Ortodon Ortop Facial 13: 43-53.

CANÇADO RH, PIZAN A, JANSON G, HENRIQUES JFC, NEVES LS AND CANUTO CE. 2009. Eficiência dos protocolos de tratamento em uma e duas fases da má oclusão de Classe II, divisão 1. R Dental Press Ortodon Ortop Facial 14: 61-79.

CAPRIOGLIO A, BERGAMINI C, FRANCHI L, VERCELLINI N, ZECCA PA, NUCERA R AND FASTUCA R. 2017. Prediction of Class II improvement after rapid maxillary expansion in early mixed dentition. Prog Orthod 18: 9.

CIGER S, AKSU M AND GERMEÇ D. 2005. Evaluation of posttreatment changes in Class II Division 1 patients after nonextraction orthodontic treatment: Cephalometric and model analysis. Am J Orthod Dentofac Orthop 127: 219223.

COSTA-JÚNIOR FM AND MAIA ACB. 2009. Concepções de Homens Hospitalizados sobre a Relação entre Gênero e Saúde. Psic Teor e Pesq 25: 55-63.

DA SILVA-FILHO OC AND DA SILVA MP. 2013. Transtornos de ansiedade em adolescentes: considerações para a pediatria e hebiatria. Adolesc Saúde 10: 31-41.

DA SILVA-FILHO OG, BERTOZ FA, FILHO LC AND ALMADA EC. 2009. Crescimento facial espontâneo Padrão II: estudo cefalométrico longitudinal. Rev Dent Press Ortodon Ortop Facial 14: 40-60.

DOLCE C, SCHADER RE, MCGORRAY SP AND WHEELER TT. 2005. Centrographic analysis of 1-phase versus 2-phase treatment for Class II malocclusion. Am J Orthod Dentofacial Orthop 128: 195-200.

DUGONI SA. 1998. Comprehensive mixed dentition treatment. Am J Orthod Dentofacial Orthop 113: 75-84.

DUGONI SAAND LEE JS. 1995. Mixed dentition case report. Am J Orthod Dentofacial Orthop 107: 239-244.

FABER J AND SALLES F. 2006. Sugical-orthodontic treatment of Class II dentofacial deformity: A case report. Rev Clín Ortod Dental Press 5: 59-69.

FRANCHI L, BACCETTI T AND MCNAMARA JR JA. 1999. Treatment and posttreatment effects of acrylic splint Herbst appliance therapy. Am J Orthod Dentofac Orthop 115: 429-438.

GIMENEZ CMM, BERTOZ AP AND BERTOZ FA. 2007. Tratamento da má oclusão de Classe II, divisão 1 de Angle, com protrusão maxilar utilizando-se recursos ortopédicos. R Dental Press Ortodon Ortop Facial 12: 85-100.
HIGA RH AND HENRIQUES JFC. 2015. Tratamento da má oclusão de Classe II com Distal Jet e aparelho fixo. Orthod Sci Pract 8: 355-362.

KING GJ, KEELING SD, HOCEVAR RA AND WHEELER TT. 1990. The timing of treatment for Class II malocclusions in children: a literature review. Angle Orthod 60: 87-97.

KOPECKY GR AND FISHMAN LS. 1993. Timing of cervical headgear treatment based on skeletal maturation. Am J Orthod Dentofacial Orthop 104: 162-169.

LIVIERATOS FA AND JOHNSTON JR LE. 1995. A comparison of one-stage and twostage nonextraction alternatives in matched Class II samples. Am J Orthod Dentofacial Orthop 108: 118-131.

MARQUES LS, BARBOSA CC, RAMOS-JORGE ML, PORDEUS IA AND PAIVA SM. 2005. Malocclusion prevalence and orthodontic treatment need in 10-14-yearold schoolchildren in Belo Horizonte, Minas Gerais State, Brazil: a psychosocial focus. Cad Saúde Publica 21: 10991106.

MOTT ML, FABERGÉ AOS, APARECIDA MM, SOUZA MLV, FERREIRA SAP AND KARLA M. 2008. Moças e senhoras dentistas: formação, titulação e mercado de trabalho nas primeiras décadas da República. História, Ciências, Saúde 15: 97-115.

NGAN PW, BYCZEK E AND SCHEICK J. 1997. Longitudinal evalution of growth changes in class II division 1 subjects. Semin Orthod 3: 222-231.

NUNES MF, LELES CR AND GONÇALVES MM. 2010. Gênero e Escolha por Especialidades Odontológicas: Estudo com Egressos de uma Universidade Pública. Rev Odontol Bras Central 19: 142-145.

PARANHOS LR, RICCI ID, BITTAR TO, SCANAVINI MA AND RAMOS AL. 2009. Análise do mercado de trabalho odontológico na região sul do Brasil. Rev Fac Odontol UPF 14: 7-13.

PARANHOS LR, SALAZAR M, KOIDE RE AND RAMOS AL. 2008. Análise do mercado de trabalho de cirurgiõesdentistas, clínicos-gerais e especialistas em Ortodontia, nos Estados brasileiros. Rev Clín Ortodon 7: 79-85.

PARANHOS LR, SALAZAR M, TORRES CF, PEREIRA AC, DA SILVA RF AND RAMOS AL. 2011. Avaliação do perfil dos profissionais da área de Ortodontia quanto às condutas legais. Dental Press J Orthod 16: 127-134.

PAVLOW SS, MCGORRAY SP, TAYLOR MG, DOLCE C, KING GJ AND WHEELER TT. 2008. Effect of early treatment on stability of occlusion in patients with Class II malocclusion. Am J Orthod Dentofac Orthop 133: 235 244.

PIETILA T AND PIETILA I. 1994. Parents' views on their own child's dentition compared with an orthodontist's assessment. Eur J Orthod 16: 309-316.

PONTES LF, MAIA FA, ALMEIDA MR, FLORES-MIR C AND NORMANDO D. 2017. Mandibular Protraction 
Appliance Effects in Class II Malocclusion in Children, Adolescents and Young Adults. Braz Dent J 28: 225-233.

POPOWICH K, NEBBE B, HEO G, GLOVER KE AND MAJOR PW. 2005. Predictors for Class II treatment duration. Am J Orthod Dentofacial Orthop 127: 293-300.

POSSOBON RF, DE MORAES ABA, AMBROZANO GMB AND JUNIOR ALC. 2004. O comportamento de crianças em tratamento odontológico: intervenção psicofarmacológica. Psicol Estud 9: 29-35.

PROFFIT WR AND TULLOCH JF. 2002. Preadolescent Class II problems: treat now or wait? Am J Orthod Dentofacial Orthop 121: 560-562.

QUAGLIO CL, HENRIQUES RP, HENRIQUES JFC AND DE FREITAS MR. 2009. Classe II divisão 1 associada à deficiência transversal maxilar. Tratamento com disjuntor tipo Hyrax e aparelho de Herbst: relato de caso clínico. Rev Dental Press Ortodon Ortop Facial 14: 118-128.

RUF S AND PANCHERZ H. 2003. When Is the Ideal Period for Herbst Therapy-Early or Late? Semin Orthod 9: 47-56.

SHARMA JN. 2009. Epidemiology of malocclusions and assessment of orthodontic treatment need for the population of eastern nepal. World J Orthod 10: 311-316.
SIARA-OLDS NJ, PANGRAZIO-KULBERSH V, BERGER J AND BAYIRLI B. 2010. Long-term dentoskeletal changes with the Bionator, Herbst, Twin Block, and MARA functional appliances. Angle Orthod 80: 18-29.

SILVA-FILHO OG, AIELLO CA AND FONTES MV. 2005. Aparelho Herbst: Protocolos de tratamento precoce e tardio. R Dental Press Orthodon Ortoped Facial 10: 30-45.

SINGER J. 1980. Physiologic timing of orthodontic treatment. Angle Orthod 50: 322-333.

SPALJ S, TRANESEN KM, BIRKELAND K, KATIC V, PAVLIC A AND VANDEVSKA-RADUNOVIC V. 2017. Comparison of Activator-Headgear and Twin Block Treatment Approaches in Class II Division 1 Malocclusion. Biomed Res Int: 1-9.

WEISS J AND EISER HM. 1977. Psychological timing of orthodontic treatment. Am J Orthod 72: 198-204.

WHITE L. 1998. Early orthodontic intervention. Am J Orthod Dentofacial Orthop 113: 24-28.

WIESLANDER L. 1993. Long-term effect of treatment with the headgear-Herbst appliance in the early mixed dentition. Stability or relapse? Am J Orthod Dentofacial Orthop 104: 319-329. 